This item was submitted to Loughborough's Research Repository by the author.

Items in Figshare are protected by copyright, with all rights reserved, unless otherwise indicated.

\title{
Correcting mass measurement of diesel particulate filters at non-ambient temperatures
}

PLEASE CITE THE PUBLISHED VERSION

PUBLISHER

Professional Engineering Publishing / @ IMECHE

VERSION

VoR (Version of Record)

\section{LICENCE}

CC BY-NC-ND 4.0

\section{REPOSITORY RECORD}

Williams, Andrew M., and Colin P. Garner. 2019. "Correcting Mass Measurement of Diesel Particulate Filters at Non-ambient Temperatures”. figshare. https://hdl.handle.net/2134/4838. 
This item was submitted to Loughborough's Institutional Repository (https://dspace.lboro.ac.uk/) by the author and is made available under the following Creative Commons Licence conditions.

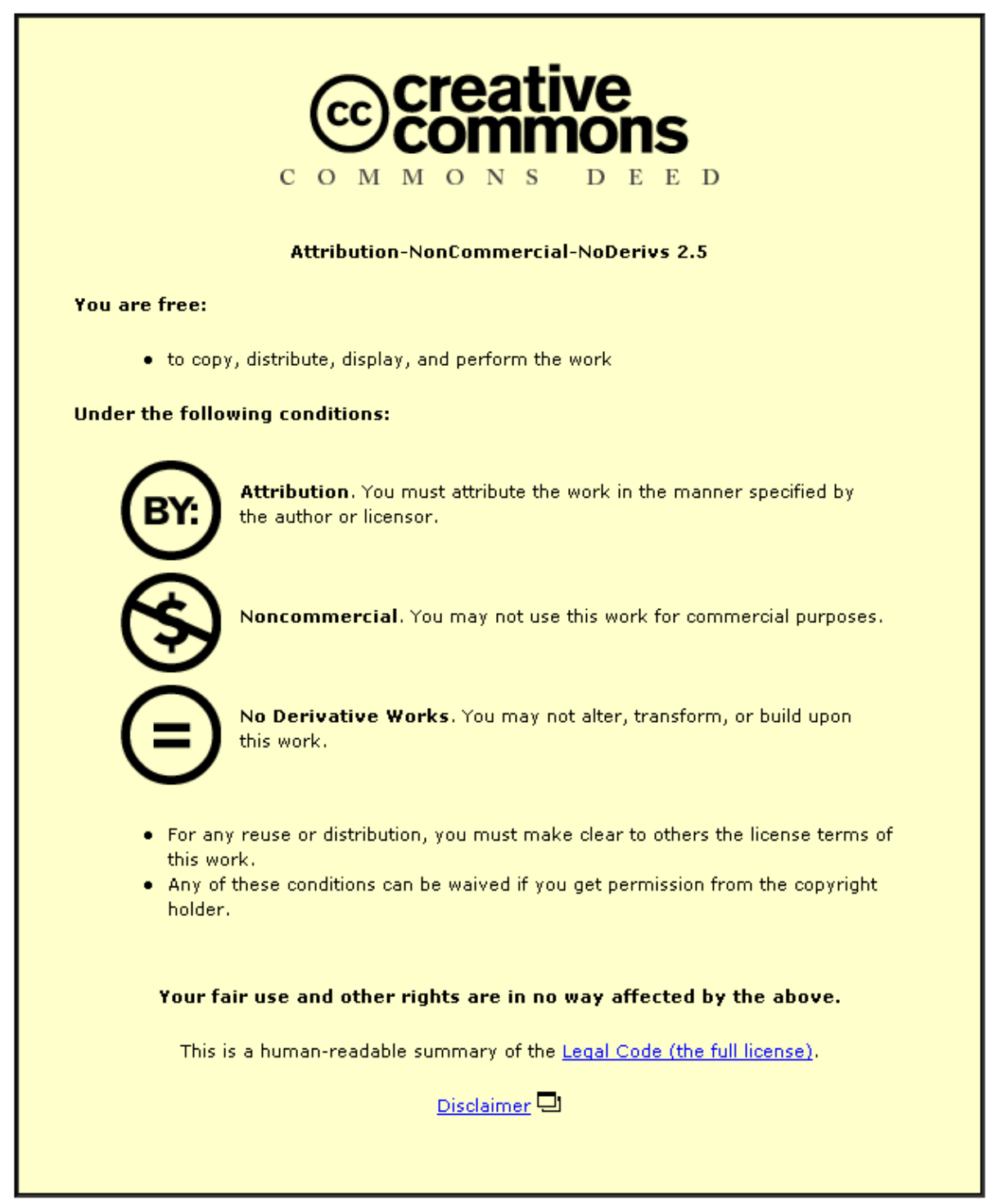

For the full text of this licence, please go to: http://creativecommons.org/licenses/by-nc-nd/2.5/ 


\title{
Correcting mass measurement of diesel particulate filters at non-ambient temperatures
}

\author{
A M Williams* and C P Garner \\ Wolfson School of Mechanical and Manufacturing Engineering, Loughborough University, Loughborough, UK
}

The manuscript was received on 18 February 2008 and was accepted after revision for publication on 30 September 2008.

DOI: 10.1243/09544070JAUTO834

\begin{abstract}
Diesel particulate filters (DPFs) are becoming a widespread method for reducing the particulate matter (PM) emissions from both on-highway and off-highway automotive diesel engines. Mass measurements of DPFs are commonly used to determine rapidly both the amount of PM trapped by the filter and the amount regenerated (removed) by regeneration systems. To avoid issues with adsorption of atmospheric water the filters are often weighed at elevated temperatures. It is shown in this work that at elevated temperatures the filters weigh less than at lower temperatures as a direct result of the buoyant hot air within the filter substrate. This study shows that consideration of the buoyancy forces allows for correction of the mass measurement for the errors relating to the non-ambient temperature of the filter, allowing mass measurements at elevated temperatures while avoiding adsorption of atmospheric water on to the filter substrate and, therefore, improving the accuracy of mass-measurement-based studies of filtration and regeneration performance of DPFs. It is demonstrated that a filter with approximately 85 per cent overall porosity weighed at $150^{\circ} \mathrm{C}$ in ambient temperatures will have an error of about $0.3 \mathrm{~g} / 1$ (typically about 10 per cent of the trapped PM mass) in the mass measurement when not correcting for the temperature. By way of an example, this is shown to have potentially an important effect on the calculated trapped PM.
\end{abstract}

Keywords: diesel particulate filter, wall flow filter, particulate matter, mass measurement, ceramic foam, buoyancy, correction, non-ambient temperature

\section{INTRODUCTION}

Increasing awareness of the health impacts of diesel engine particulate matter (PM) emissions $[\mathbf{1}, 2]$ has led to stringent legislation limiting the engine-out quantities of PM emitted from automotive sources. Increasing fuel injection pressure [3] and optimal use of exhaust gas recirculation [4] (among other combustion controls) can significantly reduce the engine-out PM. However, it is anticipated that, even with in-cylinder methods, exhaust gas after-treatment will be needed to achieve future PM emission legislative targets [5]. This has driven a large amount of research into diesel particulate filtration technol-

*Corresponding author: Wolfson School of Mechanical and Manufacturing Engineering, Loughborough University, Loughborough, Leicestershire, LE11 3TU, UK. email: a.m.williams@ lboro.ac.uk ogies such as monolithic wall flow [6], metallic substrate [7], and ceramic foam [8] diesel particulate filters (DPFs). As the quantity of PM in DPFs increases, the exhaust flow pressure drop across the filter increases. To maintain acceptable engine performance and efficiency the filters need periodic cleaning (regeneration) to oxidize or remove the PM from the filtration surface. Regenerating DPFs in an efficient, reliable, effective, and low-cost way is the focus of a large amount of research effort (see, for example, references [9] to [13]).

Development of existing and new filtration substrates often involves mass measurements of the clean filter and PM-loaded filter to determine filtration efficiency of the filter [14]. Measurement resolution and accuracy of less than $0.1 \mathrm{~g}$ for a range greater than $1000 \mathrm{~g}$ are typically required, which means that tight control of potential errors is essential. Similarly, regeneration system performance is often evalu- 
ated by weighing a PM-loaded DPF before and after a regeneration event [15-17] with similar levels of accuracy required.

Care is generally taken to measure the PM-loaded filters in a dry state by heating the filter sample and removing adsorbed water and volatile components to allow comparative measurements [14]. To prevent adsorption of water from the atmosphere on to the dry PM the filter mass is often measured above ambient temperatures. This has been observed by the present authors to lead to an underestimate of the mass of the filter and PM which can reflect both positively and negatively on the quoted filtration and regeneration performance of DPF systems. The physical cause of this error in mass measurement is described in this paper. The understanding of the origin of this error has been used to develop methodology for correcting the mass measurement of the sample measured at non-ambient temperatures, allowing accurate mass measurements of PMloaded DPFs without risking adsorption of atmospheric water affecting the results.

The development of this mass correction method is motivated by the need to compare diesel particulate filtration and regeneration characteristics rapidly and easily when the only available method is by pre- and post-weighing of the sample. Many researchers are aware of the need to preheat the sample if a 'dry' PM mass measurement is needed; however, to the authors' knowledge, a clear method to correct for the buoyancy effect described in this paper has not yet been published. This method will, therefore, enable more accurate evaluation of new DPF filtration and regeneration systems when relying on pre- and post-weight measurements.

\section{EXPERIMENTAL METHOD}

Samples of clean and PM-loaded monolithic wall flow filters (WFFs) and ceramic foam filters were used to study the effect of non-ambient filter temperature on mass measurements. The specifications of the filter samples are shown in Table 1. The WFF samples considered had 100 cells $/ \mathrm{in}^{2}$ (about 15.5 cells $/ \mathrm{cm}^{2}$ ) with an average pore diameter of approximately $13 \mu \mathrm{m}$. The gelcast ceramic foams had an average pore diameter of approximately $450 \mu \mathrm{m}$.

Samples 2 and 4 were loaded with PM by installing a DPF of $5.66 \mathrm{in}(144 \mathrm{~mm})$ diameter in the exhaust flow of a Perkins 1100 series, tier 2, 4.41, turbocharged, charge-cooled, heavy-duty diesel engine at $1400 \mathrm{r} / \mathrm{min}$ and $100 \mathrm{Nm}$. Once the desired filter volume specific PM mass loading was achieved, the samples were removed from the exhaust system and smaller samples cut from them. Smaller samples were used to enable higher-resolution mass measurements to be made than are achievable with a full-scale analytical balance greater than $1.5 \mathrm{~kg}$. The PM composition was not analysed and was assumed to be the non-volatile PM components trapped by the DPF. This is justified by noting that before mass measurements begin, the filters were preheated to higher than $180^{\circ} \mathrm{C}$, which removed the volatile component of the PM. As the sample cools, atmospheric water may adsorb or absorb to the PM, increasing the apparent mass. This is not considered in the correction method and will be seen later in this paper to be typically a small effect relative to the buoyancy effect.

The samples were heated using a hot-air blower until a relatively even substrate temperature of higher than $180^{\circ} \mathrm{C}$ was achieved, as measured with a K-type thermocouple in various locations within the filter volume. The filter samples were then insulated with a glass fibre matting insulation to prevent the formation of any significant temperature gradients through the substrate. The samples were slowly allowed to cool over approximately $60 \mathrm{~s}$ intervals before the mass was determined on a calibrated KERN ARJ 220-4NM analytical balance with a resolution of $0.2 \mathrm{mg}$ over a $220 \mathrm{~g}$ range.

\section{CORRECTION METHODOLOGY}

The open pore structure of the DPF and PM materials allows gas to flow through the substrate. Considering the case when a filter sample is being weighed (outside the engine exhaust) and the temperature of the substrate is different from that of the surrounding gas, the gas within the filter is heated and there is a buoyancy force on the hot gas that causes it to move through the filter. As the gas moves past the solid surfaces (both the filter and the $\mathrm{PM})$, a drag force is applied to the material in the direction of the flow. This is shown schematically in the cross-section in Fig. 1. In the case of a hot filter, this would lead to a net drag force that reduces the weight of the sample and affects the results of mass comparisons at different temperatures.

The natural convective flow during the mass measurement rapidly reaches equilibrium conditions. This is observed by the constant sample weight for a fixed temperature. If the trapped air within the filter were accelerating, the observation would show a reducing sample weight as the trapped air velocity 
Table 1 Test filter material specifications

\begin{tabular}{lllll}
\hline Sample & $\begin{array}{l}\text { Filtration } \\
\text { media }\end{array}$ & Material & $\begin{array}{l}\text { Overall } \\
\text { porosity (\%) }\end{array}$ & $\begin{array}{l}\text { Sample } \\
\text { volume (l) }\end{array}$ \\
\hline 1 & WFF & Cordierite & $\approx 79$ & 0.38 \\
$2^{*}$ & WFF & Cordierite & $\approx 79$ & 0.09 \\
3 & Ceramic foam & Mullite & $\approx 82$ & 0.10 \\
$4^{*}$ & Ceramic foam & Cordierite & $\approx 80$ & 0.12 \\
\hline
\end{tabular}

*PM loaded.

increased. Once equilibrium conditions are reached, the buoyancy force on the non-ambient temperature gas is equally matched by the drag force on the filter substrate, and the proposed correction methodology is valid. As the resistance to flow changes (e.g. higher PM loadings) the flow velocity will reduce but, when the equilibrium condition is rapidly reached, the forces will still balance. Therefore, the correction method is independent of PM loading provided that any significant changes in overall porosity are accounted for in the final equations.

The buoyancy force $F_{\mathrm{b}}$ can be calculated from the displaced mass $m_{\mathrm{a}}$ of air as

$$
F_{\mathrm{b}}=m_{\mathrm{a}} g
$$

where $g$ is the acceleration due to gravity. The dis-

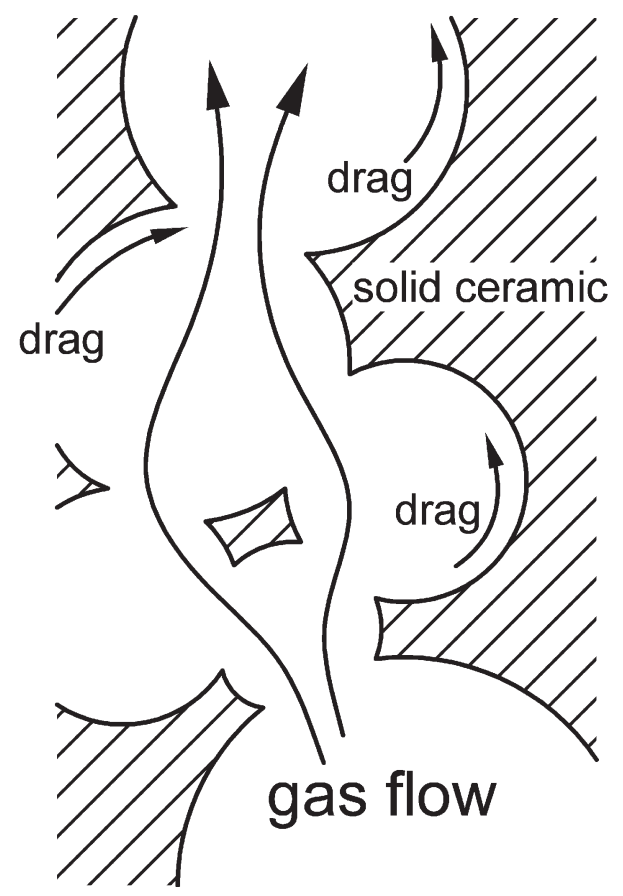

Fig. 1 Schematic diagram showing the flow through the porous structure and the subsequent drag forces on the solid substrate placed mass of air can be found by considering the change in mass of a fixed volume of air at constant pressure for a change in temperature according to

$$
m_{\mathrm{a}}=\frac{P V}{R_{\mathrm{air}}}\left(\frac{1}{T_{\mathrm{r}}}-\frac{1}{T_{\mathrm{a}}}\right)
$$

where $P$ is the gas pressure, $V$ is the control volume size, $R_{\text {air }}$ is the gas constant of air, $T_{\mathrm{r}}$ is the reference temperature (i.e. ambient air temperature), and $T_{\mathrm{a}}$ is the air temperature within the filter substrate. The volume of air is a function of the porosity $\varepsilon$ of the filter and the filter volume $V_{\mathrm{f}}$, such that

$$
V=\varepsilon V_{\mathrm{f}}
$$

The buoyancy force is therefore

$$
F_{\mathrm{b}}=\frac{\varepsilon P V_{\mathrm{f}}}{R_{\mathrm{air}}}\left(\frac{1}{T_{\mathrm{r}}}-\frac{1}{T_{\mathrm{a}}}\right) g
$$

The weight $F$ of the sample is

$$
F=m g-F_{\mathrm{b}}
$$

An analytical balance would display the mass calculated as

$$
m_{\text {display }}=\frac{F}{g}=m-\frac{F_{\mathrm{b}}}{g}
$$

The error $E_{m}$ in the mass measurement is therefore

$$
E_{m}=\frac{\varepsilon P V_{\mathrm{f}}}{R_{\text {air }}}\left(\frac{1}{T_{\mathrm{r}}}-\frac{1}{T_{\mathrm{a}}}\right)
$$

This relationship can be used to correct for the mass measurement of non-ambient temperature DPFs as well as of other openly porous structures. If large temperature gradients are present in the sample, then the sample can be conceptually discretized to consider this. It is important to note that the porosity used in this calculation is the overall porosity of the filter. For example, in the case of a monolithic WFF, the porous volume would include the channel volume as this contributes to the buoyancy effects. This should not be confused with the porosity of the wall of the filter, which is commonly quoted. Typical PM loadings change the overall open porosity by less than 0.5 per cent owing to the high porosity of the PM. This is negligible in comparison with other uncertainties in the measurements.

This methodology was applied to the test samples in Table 1, and the results of the correction follow. 


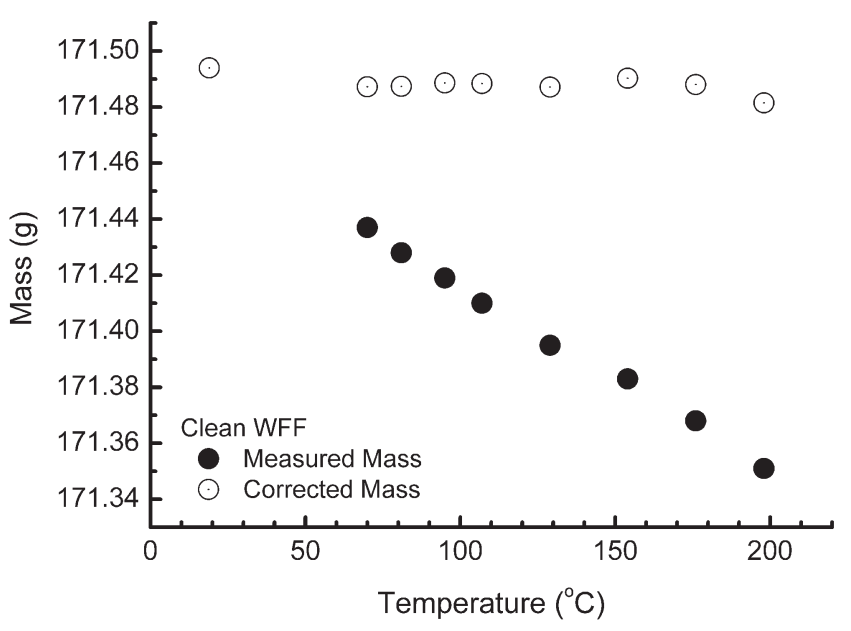

Fig. 2 Measured and corrected masses of a clean WFF sample 1 (PM loading, $0 \mathrm{~g} / \mathrm{l}$ )

\section{RESULTS}

Figures 2 and 3 show the effect of substrate temperature on the measured mass of clean wall flow and ceramic foam filter samples respectively. Both cases demonstrate the sensitivity of the measured mass to temperature when accurately measuring the mass of the sample. The corrected mass showed that equation (7) was effective at compensating for the reduced weight of the hot sample and can be used to allow accurate comparisons of sample mass when measuring at non-ambient temperatures.

Figures 4 and 5 show the effect of substrate temperature on the measured mass of PM-loaded wall flow and ceramic foam filter samples respectively. The loaded samples were used to identify

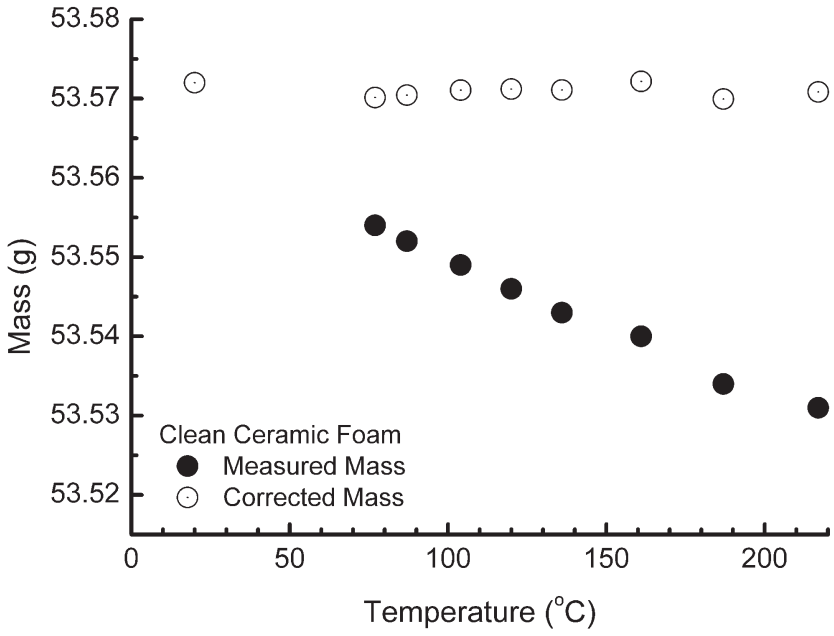

Fig. 3 Measured and corrected masses of a clean ceramic foam DPF sample 3 (PM loading, $0 \mathrm{~g} / \mathrm{l}$ )

whether the PM adsorbed any significant atmospheric water during cooling. Although these samples had lower PM loading than in some filter and regeneration systems, a large PM loading of about $10 \mathrm{~g} / \mathrm{l}$ would reduce the overall porosity by about 0.5 per cent and, therefore, the correction method is still valid for higher PM loadings.

The correction was observed to reduce errors in the mass measurement significantly. The data indicated that, at higher temperatures, the sample mass was still greater at lower temperatures than higher temperatures. This was likely to be a result of adsorbed water on the PM as the sample cools. Importantly, the effect of the substrate temperature

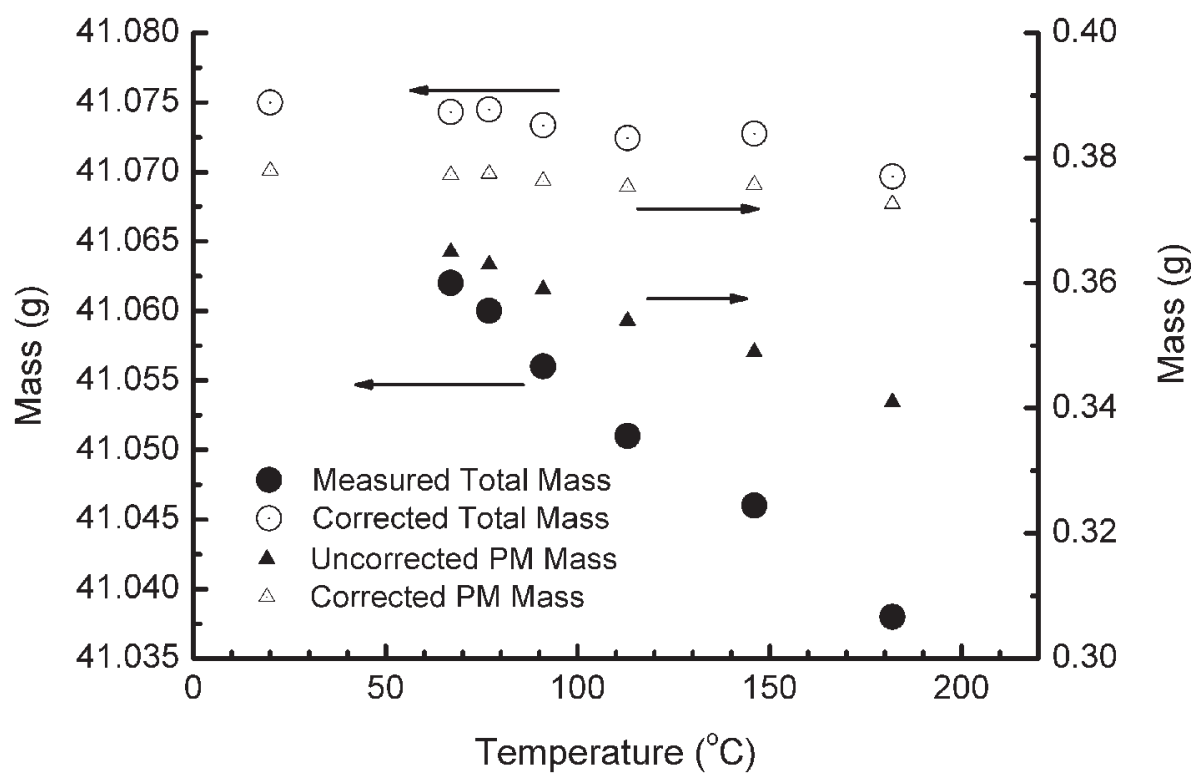

Fig. 4 Measured and corrected masses of a PM-loaded WFF sample 2 (PM loading, 4.2 g/l) 


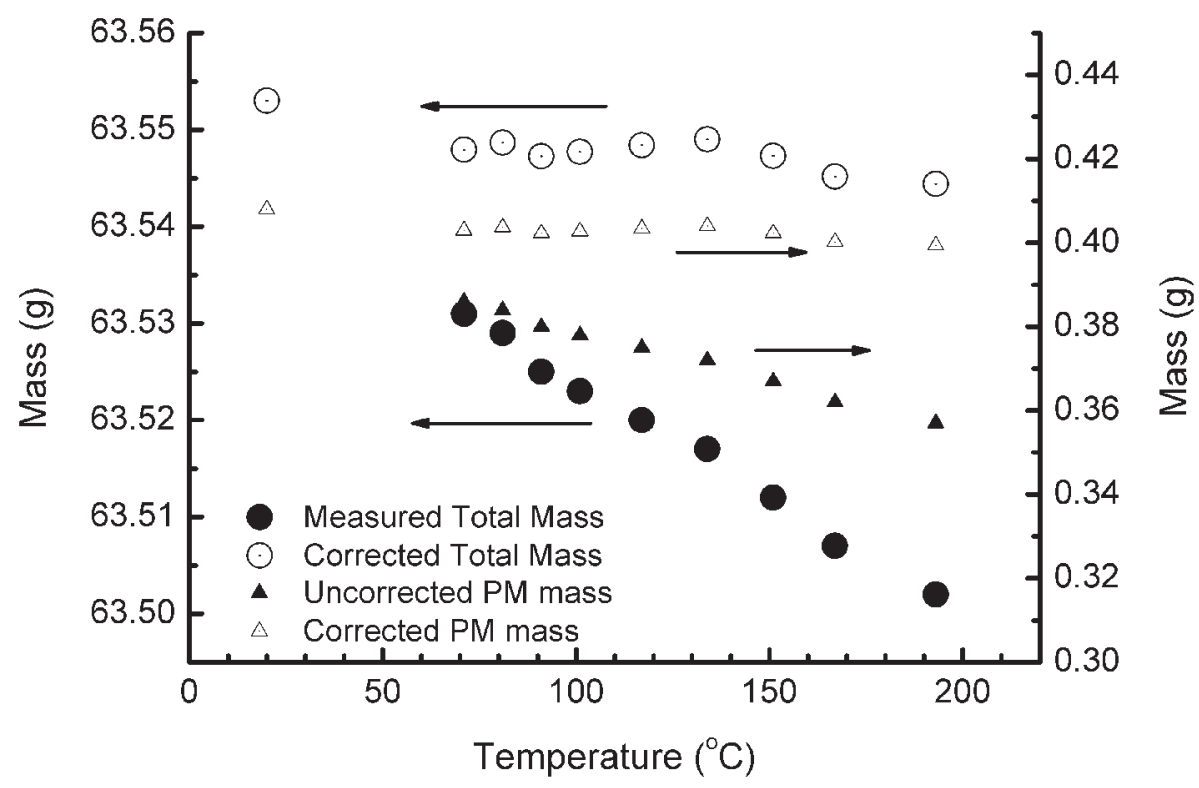

Fig. 5 Measured and corrected masses of a PM-loaded ceramic foam DPF sample 4 (PM loading, $3.4 \mathrm{~g} / \mathrm{l})$

is demonstrated to be larger than the effect of adsorption of water from the atmosphere.

Figure 6 shows the predicted relationship between the temperature and the potential error in the mass measurement for a range of porosity samples. For typical filter volumes (greater than 2.51) the error can be seen to approach more than $1 \mathrm{~g}$. This is shown by way of an example to have potentially a significant effect on DPF and regeneration system performance evaluations if the mass is not corrected for temperature.

Considering an example of the measurement of filtration efficiency of a new filter material by trapping the post-filter PM in a high-efficiency filter

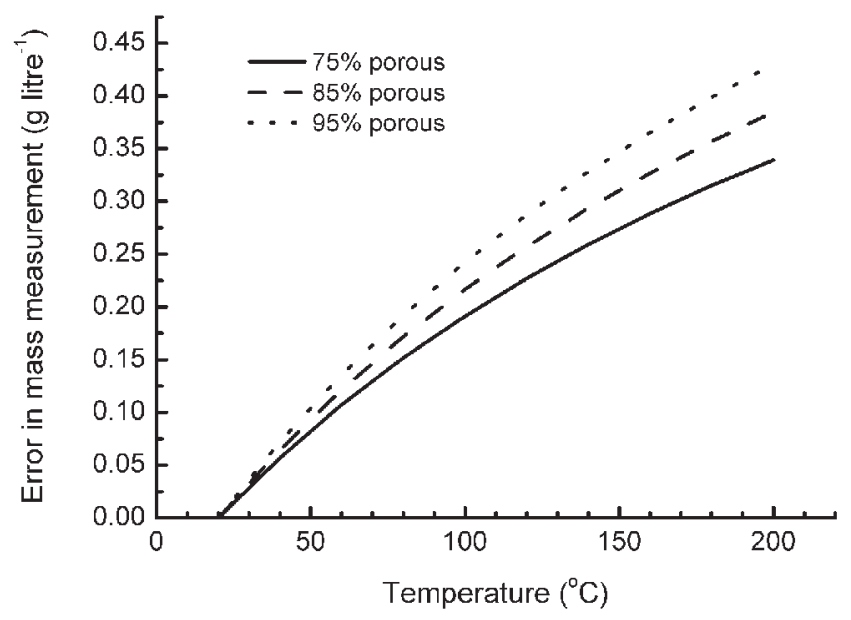

Fig. 6 Predicted effect of temperature on the mass measurement for a range of porosity samples (see, for example, reference [14]), the ratio of mass trapped on the two filter samples gives the filtration efficiency of the novel filtration material. The details of the example are shown in Table 2, which considered a typical 100 cells $/ \mathrm{in}^{2}$ (about $15.5 \mathrm{cells} / \mathrm{cm}^{2}$ ) monolithic wall flow DPF. The PM-loaded filter sample mass is measured at $150{ }^{\circ} \mathrm{C}$ to allow measurement of the dry weight. If the mass is not corrected for the temperature, the calculated PM trapped on the filter is about 10 per cent less than the actual trapped PM, significantly affecting the calculated filtration efficiency. If the correction for the filter temperature is used, the calculated trapped PM mass and hence filtration efficiency are accurate.

Similar mass-based measurements of regeneration system performance without adequate consideration of temperature effects will also lead to errors which can be avoided by the use of the correction described in this paper. In some situations this may be acceptable; however, in cases where, for example, low PM loadings are common (e.g. some burner systems) the correction becomes more important.

Table 2 Example of mass-based filtration efficiency measurements

\begin{tabular}{ll}
\hline Filter volume & $2.47 \mathrm{l}$ \\
Porosity & $79 \%$ \\
Clean filter mass & $1113 \mathrm{~g}$ \\
Trapped PM & $7.5 \mathrm{~g}$ \\
Measured (PM-loaded) mass & $1119.8 \mathrm{~g}$ \\
Apparent PM loading (without correction) & $6.8 \mathrm{~g}$ \\
\hline
\end{tabular}




\section{CONCLUSIONS}

Consideration needs to be made to the temperature of the filter sample during accurate mass measurements. Higher than ambient temperatures have been shown to result in underestimates of the DPF sample mass. This work has shown the following.

1. The measured mass of a filter sample at $150^{\circ} \mathrm{C}$ will typically be underestimated by about $0.3 \mathrm{~g} / \mathrm{l}$, which leads to errors in trapped PM mass of more than 10 per cent for typical PM filter loadings of up to $4 \mathrm{~g} / \mathrm{l}$.

2. This potential error can be significant in the evaluation of filtration and regeneration system performance.

3. The error in mass measurement is a result of the buoyant hot air within the filter rising, applying viscous drag forces to the filter sample.

4. The error in mass measurement can be corrected using equation (7), derived in this research, if the substrate temperature is known.

The use of the methodology developed in this paper to correct the mass measurement increases the accuracy of and supports effective experimental data capture.

\section{ACKNOWLEDGEMENTS}

The authors gratefully acknowledge the support of Foresight Vehicle, Caterpillar, and the Engineering and Physical Sciences Research Council during this research.

\section{REFERENCES}

1 Iwai, K., Adachi, S., Takahashi, M., Moller, L., Udagawa, T., Mizuno, S., and Sugawara, I. Early oxidative DNA damages and late development of lung cancer in diesel exhaust exposed rats. Environ. Res., Section A, 2000, 84, 225-264.

2 Ma, J. Y. C. and Ma, J. K. H. The dual effect of the particulate and organic components of diesel exhaust particles on the alteration of pulmonary immune/inflammatory responses and metabolic enzymes. J. Environ. Sci. Health, Part C - Environ. Carcinogenesis Ecotoxicol. Rev., 2002, 20, 159-170.

3 Singh, I., Zhong, L., Lai, M.-C., and Henein, N. A. Effect of nozzle hole geometry on an HSDA diesel engine-out emissions. SAE technical paper 200301-0704, 2003.

4 Kunte, S., Bertola, A., Obrecht, P., and Boulouchos, $\mathbf{K}$. Temporal soot evolution and diesel engine combustion: influence of fuel composition, injection parameters, and exhaust gas recirculation. Int. J. Engine Res., 2006, 7, 459-469.

5 Johnson, T. V. Diesel emission control in review. SAE technical paper 2006-01-0030, 2006.

6 Li, C. G., Mao, F., Swartzmiller, S. B., Wallin, S. A., and Ziebarth, R. R. Properties and performance of diesel particulate filters of an advanced ceramic material. SAE technical paper 2004-01-0955, 2004.

7 Jacobs, T., Chatterjee, S., Conway, R., Walker, A., Kramer, J., and Mueller-Haas, K. Development of partial filter technology for HDD retrofit. SAE technical paper 2006-01-0213, 2006.

8 Tutko, J. J., Lestz, S. S., Brockmeyer, J. W., and Dore, J. E. Feasibility of ceramic foam as a diesel particulate trap. SAE technical paper 840073, 1984.

9 Tao, T., Cutler, W. A., Voss, K., and Wei, Q. New catalyzed cordierite diesel particulate filter for heavy duty applications. SAE technical paper 2003-01-3166, 2003.

10 Geishoff, J., Pfeifer, M., Schafer-Sindlinger, A., Hackbarth, U., Teysset, O., Colignon, C., Salvat, O., Krieg, H., and Wenclawiak, B. W. Regeneration of catalytic diesel particulate filters. SAE technical paper 2001-01-0907, 2001.

11 Garner, C. P. and Dent, J. C. Microwave assisted regeneration of diesel particulate traps. SAE technical paper 890174, 1989.

12 Okubo, M., Kuroki, T., Miyairi, Y., and Yamamoto, T. Low-temperature soot incineration of diesel particulate filter using remote nonthermal plasma induced by a pulsed barrier discharge. IEEE Trans. Industry Applic., 2004, 40(6), 1504-1512.

13 Zelenka, P., Schmidt, S., and Elfinger, G. An active regeneration aid as a key element for safe particulate trap use. SAE technical paper 2001-01-3199, 2001.

14 Konstandopoulos, A. G., Xarvalis, D., Kladopoulou, E., and Dolios, I. A multi-reactor assembly for screening of diesel particulate filters. SAE technical paper 2006-01-0874, 2006.

15 Scott-Sluder, C. and West, B. Catalysed diesel particulate filter performance in a light duty vehicle. SAE technical paper 890170, 1989.

16 Mayer, A., Evequoz, R., Wyser-Heusi, M., Czerwinski, J., Matter, U., and Graf, P. Particulate traps used in city buses in Switzerland. SAE technical paper 2000-01-1927, 2000.

17 Barris, M. and Rocklitz, G. Development of automatic trap oxidizer muffler systems. SAE technical paper 890400, 1989.

\section{APPENDIX}

\section{Notation}

$E_{m} \quad$ error in mass measurement

$F \quad$ weight of the diesel particulate filter sample 


\begin{tabular}{|c|c|c|c|}
\hline$F_{\mathrm{b}}$ & buoyancy force & $T_{\mathrm{a}}$ & air temperature within the filter \\
\hline$g$ & acceleration due to gravity & & volume \\
\hline$m$ & $\begin{array}{l}\text { mass of the diesel particulate filter } \\
\text { sample }\end{array}$ & $T_{\mathrm{r}}$ & $\begin{array}{l}\text { reference temperature (i.e. ambient } \\
\text { air temperature) }\end{array}$ \\
\hline$m_{\mathrm{a}}$ & $\begin{array}{l}\text { mass of the air within the diesel } \\
\text { particulate filter sample }\end{array}$ & $V$ & $\begin{array}{l}\text { open volume of the diesel particulate } \\
\text { filter }\end{array}$ \\
\hline$m_{\text {display }}$ & $\begin{array}{l}\text { mass displayed on an analytical } \\
\text { balance }\end{array}$ & $V_{\mathrm{f}}$ & volume of the diesel particulate filter \\
\hline$P$ & ambient pressure & $\varepsilon$ & open porosity of the diesel \\
\hline$R_{\text {air }}$ & gas constant for air & & particulate filter \\
\hline
\end{tabular}

